\title{
Anatomical and visual outcomes of ranibizumab injections in retinal pigment epithelium tears
}

\author{
Resultados anatômicos e visuais de injeções de ranibizumab em roturas do epitélio pigmentado da retina \\ Muhammet Kazim Erol ${ }^{1}$, Ozdemir Ozdemir², Deniz Turgut Coban ${ }^{1}$, Basak Bostanci Ceran ${ }^{1}$, Esin Sogutlu Sari ${ }^{3}$
}

\begin{abstract}
Purpose: To report the anatomical and visual results in patients diagnosed as having retinal pigment epithelium (RPE) tears after receiving ranibizumab injections. Methods: Eyes diagnosed as having RPE tears with a minimum 6-month follow-up were retrospectively evaluated. Each eye was treated with at least three doses of ranibizumab at monthly intervals. Best-corrected visual acuity (BCVA), anterior segment findings, intraocular pressure, and fundus examination results were evaluated during control visits. Color fundus photography, fundus fluorescein angiographies, fundus autofluorescence, and spectral domain optical coherence tomography (SD-OCT) images were obtained. The height of pigment epithelial detachment (PED) was measured by SD-OCT.

Results: Twelve eyes with RPE tears were studied. Nine eyes (75\%) developed RPE tears during ranibizumab injections for choroidal neovascularization (eight eyes with vascularized PED and one eye with choroidal osteoma), and tears occurred in three eyes before any injections. The median number of ranibizumab injections after diagnosis of RPE tears was 3 ( $\min 2, \max 5$ ). In the most recent follow-up visit, there was no statistically significant correlation between the grade of RPE and logMAR of BCVA ( $p>0.05, r=0.112)$. Eight of twelve eyes had PED, and seven of these had irregular PED contours before injection therapy. The mean PED height was $447 \pm 122 \mu \mathrm{m}$.

Conclusions: In this series, RPE tears developed mostly after intravitreal anti-VEGF injections for vascularized PED. Increased vertical height and irregular contours of the PEDs can be risk factors for the formation of RPE tears. The continuation of anti-VEGF therapy after tear formation is beneficial for vision improvement in eyes with RPE tears.
\end{abstract}

Keywords: Macular degeneration; Retinal detachment; Retinal pigment epithelium; Intravitreal injections; Antibodies, monoclonal, humanized;Tomography, optical coherence; Vascular endothelial growth factor; Fluorescein angiography

\section{RESUMO}

Objetivo: Apresentar os resultados anatômicos e visuais de injeções de ranibizumab em pacientes que foram diagnosticados com roturas do epitélio pigmentado da retina (RPE).

Métodos: Olhos com um mínimo de seis meses de acompanhamento após diagnóstico de roturas do RPE foram avaliados retrospectivamente. Cada olho foi tratado com, pelo menos, três doses de ranibizumab em intervalos mensais. Acuidade visual com a melhor correção (BCVA), achados do segmento anterior, pressão intraocular e exames de fundo de olho foram avaliados nas visitas de controle. Retinografia colorida, angiografias fluoresceínicas, autofluorescência de polo posterior e tomografia de coerência óptica imagens de domínio espectral (SD-OCT) foram obtidos. A altura do descolamento do epitélio pigmentado (PED) foi medida com SD-OCT.

Resultados: Doze olhos com roturas do epitélio pigmentado da retina foram incluídos no estudo. Nove olhos (75\%) desenvolveram roturas do epitélio pigmentado da retina durante as injeções ranibizumab para neovascularização de coroide (oito olhos com descolamento do epitélio pigmentado vascularizado e um olho com osteoma de coroide), a rotura ocorreu em três olhos antes de quaisquer injeções. A mediana do número de injeções de ranibizumab após o diagnóstico da rotura do RPE foi de 3 (mínimo 2, máximo 5). Na visita de acompanhamento mais recente, não houve correlação estatisticamente significante entre o grau de RPE e logMAR de BCVA ( $p>0,05$, $r=0,112$ ). Oito dos doze olhos tinham descolamento do epitélio pigmentado, desses, 7 olhos tinham PEDs com contornos irregulares antes da injeção. A altura média do PED foi $447 \pm 122 \mu \mathrm{m}$.

Conclusões: Nesta série, as roturas de epitélio pigmentado da retina aconteceram principalmente após a injeção intravítrea anti-VEGF para descolamento do epitélio pigmentado vascularizado. O aumento da altura vertical e contornos irregulares dos PEDs podem ser considerados fatores de risco para a formação da rotura de epitélio pigmentado da retina.

Descritores: Degeneração macular; Descolamento retiniano; Epitélio pigmentado da retina; Injeções intravítreas; Anticorpos monoclonais humanizados; Tomografia de coerência óptica; Fator A de crescimento do endotélio vascular; Angiofluoresceinografia

\section{INTRODUCTION}

Retinal pigment epithelium (RPE) tear is a rare devastating complication of age-related macular degeneration (AMD). An RPE tear develops when the pigment epithelium detaches from the neurosensorial layer with its basement membrane and retracts ${ }^{(1)}$. RPE tears may develop spontaneously in eyes with AMD or after photocoagulation and photodynamic therapy. There are also cases reported to occur after nd:YAG laser capsulotomy and cataract surgery ${ }^{(2-4)}$. After anti-vascular endothelial growth factor (VEGF) therapies became widely used for choroidal neovascularization, the incidence of RPE tears has increased recently ${ }^{(5-7)}$. Some authors have stated that the contraction of choroidal neovascularization lying beneath the RPE after anti-VEGF injection causes this complication ${ }^{(8)}$.

RPE tears are diagnosed by clinical examination, fluorescein angiography, optical coherence tomography (OCT), and fundus autofluorescence imaging of the macula. RPE tears have a characteristic appea-
Submitted for publication: November 3, 2014

Accepted for publication: April 6, 2015

Ophthalmology Department, Antalya Education and Research Hospital, Antalya, Turkey.

Ophthalmology Department, Zekai Tahir Burak Women's Health Education and Research Hospital,

Ankara, Turkey.

${ }^{3}$ Ophthalmology Department, Faculty of Medicine, Balıkesir University, Balıkesir, Turkey.
Funding: No specific financial support was provided for this study.

Disclosure of potential conflicts of interest: None of the authors have any potential conflict of interest to disclose.

Corresponding author: Ozdemir Ozdemir. Zekai Tahir Burak Kadın Sağlı̆̆ı Eğitim ve Araştırma Hastanesi, Göz Hastalıkları Polikliniği, Talatpașa Bulvarı, Altındağ, Ankara - 06100, Turkey

E-mail: ozdemirozdemir@yahoo.com

Approved by the research ethics committee of Zekai Tahir Burak Women's Health Education and Research Hospital. Project number: Karar №: 29-24/09/2014 
rance on fluorescein angiography. During fluorescein angiography, the bare area is hyperfluorescent in the early phase and leakage does not occur, unlike choroidal neovascularization. The scrolled region of the RPE is particularly dark and blocks the underlying fluorescence. On occasion, the scrolled area of the RPE has been termed "doubly hypofluorescent." OCT scans through the retracted RPE show a very intense hyperreflectivity. A deep hyperreflectivity under the line corresponding to the RPE is evident in the area of the bare choroid. Fundus autofluorescence shows patchy or hazy hyperfluorescence $e^{(1-8)}$.

The incidence of RPE tear formation following anti-VEGF treatment has been reported to range between $1.8 \%$ and $27 \%$ in recent studies $^{(9)}$. Different treatment protocols and follow-up periods may explain the wide incidence range and difficulties in diagnosing RPE tears. In previous case studies, the spontaneous healing of RPE tears has been demonstrated by using time-domain $O C T^{(10,11)}$. In a study conducted by Caramoy et al., the use of anti-VEGFs was proposed to slow down the scarring process, prevent photoreceptor damage, and give RPE a chance to heal ${ }^{(12)}$.

In this study, we evaluated the anatomical and visual results in patients diagnosed as having RPE tears after receiving ranibizumab injections as anti-VEGF treatment.

\section{METHODS}

The charts of 12 eyes of 12 choroidal neovascularization patients with at least 6 months follow-up after being diagnosed with RPE tears were retrospectively evaluated. This study was conducted in accordance with the ethical principles of the Declaration of Helsinki. All patients signed an informed consent form before undergoing any treatment.

Full ophthalmic examination, including best-corrected visual acuity $(B C V A)$, anterior segment, and fundus and intraocular pressure were evaluated at the initial visit. Spectral domain (SD)-OCT was taken by using a Cirrus HD-OCT (Carl Zeiss Meditec Inc., Germany). The height of pigment epithelial detachment (PED) was evaluated by using SD-OCT, as previously described by Chan et al. ${ }^{(5)}$. Fundus photos, fundus autofluorescent images, and fundus fluorescein angiographies of the eyes were obtained by using a Visucam NM/FA fundus camera (Carl Zeiss, Dublin, California) in $45^{\circ}$ mode.

In our clinic, patients diagnosed with choroidal neovascularization receive ranibizumab (Lucentis, Genentech Inc., San Francisco, CA, USA injections $(0.5 \mathrm{mg} / 0.5 \mathrm{ml})$ at monthly intervals for the first 3 -month period. After the third injection, eyes with more than a $50-\mu \mathrm{m}$ increase in central foveal thickness and/or one or more lines of visual acuity loss on a Snellen chart receive repeated injections. This treatment protocol was not changed for patients who developed RPE tears during ranibizumab therapy.

RPE tears were graded as described by Sarraf et al..(13) . The grading was performed on the basis of the greatest length of a defect in the vector direction of the tear and foveal involvement by using fluorescein angiographic analysis: Grade 1 tears (diameter $<200 \mu \mathrm{m}$ ), Grade 2 tears (diameter between $200 \mu \mathrm{m}$ and 1 disc diameter), Grade 3 tears (diameter >1-disc diameter), and Grade 4 tears (Grade 3 tears that involved the foveal center).

\section{Statistical analysis}

Statistical analysis was performed by using a computer program (SPSS 18.0; SPSS Inc., Chicago, IL, USA). Results are reported as the mean \pm standard deviation (SD), median, minimum (min), maximum (max), frequency, or percentage. BCVA results were converted to logMAR for statistical evaluation. The Wilcoxon signed rank t-test was used for comparisons. The correlations between the grade of the RPE tear and BCVAs in the first and last follow-ups were assessed by using Spearman's rank correlation coefficient. A p value of $<0.05$ and an $r$ value of $>0.5$ were considered to indicate statistical significance.

\section{RESULTS}

Twelve eyes of 12 patients were diagnosed as having RPE tears. The demographic properties of the patients are shown in table 1. Seven (58\%) of the 12 patients were females. The mean age of the patients was $68.5 \pm 14.5$ years. Nine eyes (75\%) developed RPE tears during ranibizumab injections. The median number of ranibizumab injections before RPE tears for nine eyes was 2 (min 1, max 3). Eight of the nine eyes with RPE tears had choroidal neovascularization with vascularized PED secondary to AMD, and the other one had choroidal neovascularization secondary to choroidal osteoma. The other three eyes with RPE tears were referred to our clinic from another hospital. Therefore, it was unknown whether PED existed before RPE tear formation. The patient histories of these patients showed that there were developments of choroidal neovascularization after cataract surgery (in one eye 15 days later and in two eyes 1 year later).

The mean follow-up time after the diagnosis of RPE tears was 12.1 \pm 4.9 months. The median ranibizumab injection after the diagnosis of RPE tears was 3 ( $\min 2$, max 5). In all of the patients, ranibizumab was used as an anti-VEGF treatment agent. In the last follow-up visit, the BCVAs of the patients (logMAR $0.60 \pm 0.52$ ) were better than

Table 1. Characteristics, best-corrected visual acuity, grade of RPE tears, and numbers of ranibizumab injections of the patients

\begin{tabular}{|c|c|c|c|c|c|c|c|c|}
\hline Patient no & Age & Sex & $\begin{array}{c}\text { First BCVA } \\
\text { (logMAR) }\end{array}$ & $\begin{array}{l}\text { Last BCVA } \\
\text { (logMAR) }\end{array}$ & $\begin{array}{l}\text { Grade of } \\
\text { RPE tear }\end{array}$ & $\begin{array}{l}\text { Number of ranibizumab } \\
\text { injections before RPE tear }\end{array}$ & $\begin{array}{l}\text { Number of ranibizumab } \\
\text { injections after RPE tear }\end{array}$ & $\begin{array}{c}\text { Mean PED height } \\
\text { (micron) }\end{array}$ \\
\hline 1 & 72 & $M$ & 1.0 & 0.1 & 1 & 0 & 4 & No PED \\
\hline 2 & 76 & F & 0.2 & 0.1 & 1 & 2 & 3 & 344 \\
\hline 3 & 57 & M & 0.3 & 0.1 & 2 & 2 & 3 & 387 \\
\hline 4 & 71 & $\mathrm{~F}$ & 0.7 & 0.5 & 3 & 1 & 3 & 402 \\
\hline 5 & 75 & $\mathrm{~F}$ & 0.7 & 0.7 & 2 & 2 & 2 & 498 \\
\hline 8 & 75 & $\mathrm{~F}$ & 0.7 & 1.3 & 4 & 0 & 5 & No PED \\
\hline 9 & 74 & M & 0.4 & 0.4 & 3 & 2 & 3 & 230 \\
\hline 10 & 29 & F & 1.0 & 0.7 & 2 & 2 & 2 & No PED \\
\hline 11 & 68 & $\mathrm{~F}$ & 1.0 & 0.7 & 3 & 2 & 5 & 455 \\
\hline 12 & 81 & M & 2.0 & 0.9 & 2 & 3 & 3 & 578 \\
\hline
\end{tabular}


those at the first follow-up visit (logMAR $0.85 \pm 0.45)$; however, the difference was not statistically significant ( $p=0.12$ ). The median grade of the RPE tears was 2.5 (range, 1-4). In the last follow-up visit, there was a positive correlation between the RPE grade and logMAR BCVA, but the correlation was not statistically significant ( $p>0.05, r=0.112$ ).

In five of the nine eyes that developed RPE tears during ranibizumab therapy, subretinal hemorrhages were evident. Five of these eyes developed RPE tears after the second injection, and two eyes hemorrhaged after the first dose. After tear development, hemorrhage was observed in only two eyes.

During the follow-up period, the RPEs (one Grade 1 and one Grade 2) in two eyes reattached. In these eyes, reattachments of RPE tears were observed by using SD-OCT and fundus autofluorescence imaging. Initially, the RPE tear areas were hypoautofluorescent and the tear borders were hyperautofluorescent. However, in the last visit, it was observed in two eyes that the hypoautofluorescence initially observed in the tear area had changed to hyperautofluorescence, and in one of the eyes, hyperautofluorescent spots were still evident in the hypoautofluorescent area. Eight of the twelve eyes with RPE tears had PED. The mean PED height of the eight eyes was $447 \pm 122 \mu \mathrm{m}$ initially. The PEDs of seven of these eyes had irregular contours.

\section{Representative case examples}

Case 3: A 57-year-old man was admitted to our clinic with vision loss in the left eye. The BCVA in the left eye was 1.0 logMAR. On the basis of the OCT and fundus fluorescein angiography findings, he was diagnosed with $A M D$, and an intravitreal ranibizumab treatment protocol was started. When his BCVA improved to 0.3 logMAR after the second dose, a Grade 2 RPE tear was observed in the inferior macula. Two doses of ranibizumab were administered after tear formation. Six months later, his BCVA improved to 0.1 logMAR. In fundus autoflorescence imaging, there was hyperautofluorescent spotting in the denuded RPE area, and subretinal and intraretinal hyper-reflective spots were seen in the OCT (Figure 1).
Case 9: A 74-year-old male was with vision loss in both eyes was examined. His BCVA indicated the ability to count fingers at $1 \mathrm{~m}$ in the right eye and to count fingers at $2 \mathrm{~m}$ in the left eye. Fundus examination in the right eye revealed two disc-sized subretinal hemorrhages on the macula. He was diagnosed with AMD. After the second dose of ranibizumab, the subretinal hemorrhage was resorbed, BCVA increased to 0.4 logMAR (Figure 2 A), but OCT revealed an RPE tear (Figure $2 \mathrm{~B}$ ). Three additional ranibizumab injections were administered after tear formation, and his BCVA remained stable at $0.4 \log M A R$ (Figures 2 ( and 2 D).

\section{DISCUSSION}

We observed that nine of the 12 eyes developed RPE tears during the treatment of choroidal neovascularization with ranibizumab injections. We continued to inject intravitreal ranibizumab after the development of RPE tears. After all injections, two of the 12 eyes appeared to be stable, nine of the 12 eyes showed improvement, and only one eye showed worsening of visual acuity at the end of the follow-up periods. At the last follow-up visits, however, the visual acuity had decreased in the patients with a high degree of tears, but the decrease was not statistically significant. According to our experience, continuation of anti-VEGF injections for patients who developed RPE tears during injection therapy appears to be necessary. In our study population, the heights of the PEDs were $>400$ microns, and PEDs in seven of the eight eyes had irregular contours.

The pathogenesis of RPE tears is not fully understood. Contraction of the choroidal neovascularization under the weak RPE, increased fluid transport secondary to exudative AMD under the RPE, globe deformation, vitreous syneresis, vitreo-macular traction due to vitreous incarceration in the injection hole, and detachment of the tight junctions between RPE cells are some of the mechanisms that have been considered ${ }^{(14,15)}$

RPE tears usually develop from the temporal edge of the PED. The separated part of the RPE folds parallel to the PED and reveals the
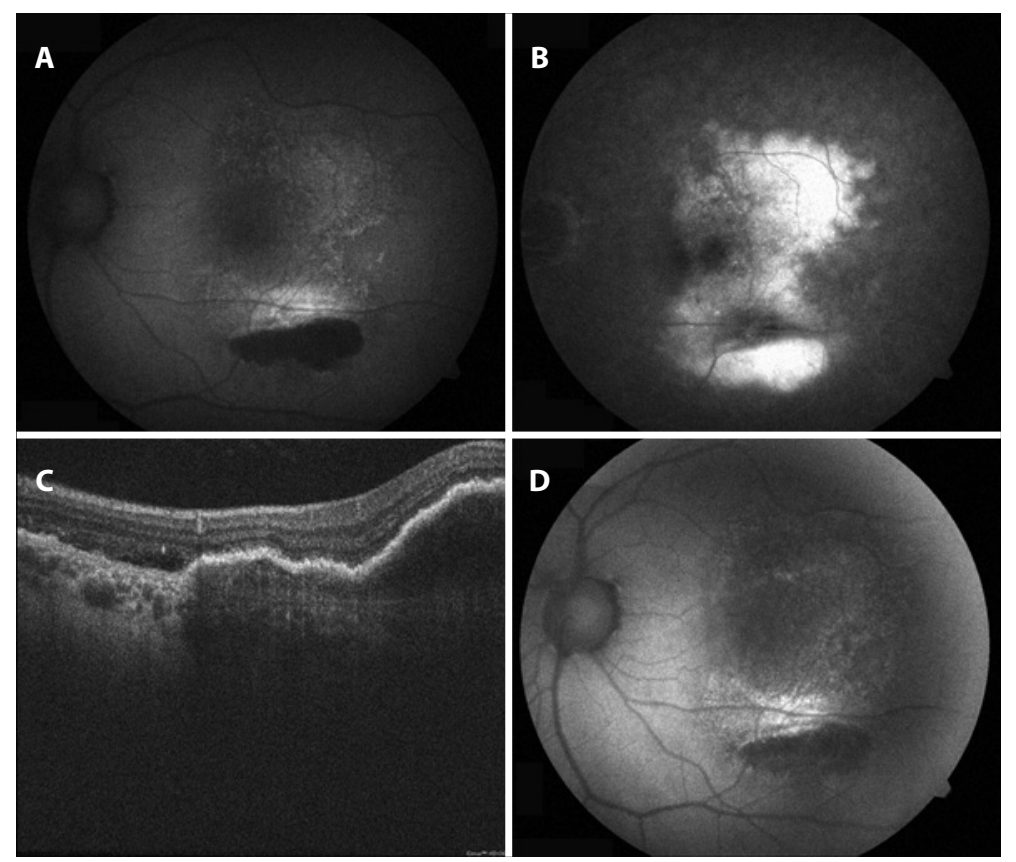

Figure 1. A) Fundus autofluorescent imaging of the left eye in case 3. The retinal pigment epithelium (RPE) tear in the inferior macula is hypoautofluorescent, and the denuded RPE area shows spotted hyperautofluorescence. B) In fluorescein angiography, the RPE tear in the inferior macula is hyperfluorescent, and the denuded RPE area is hypofluorescent. C) The spectral domain optical coherence tomography (SD-OCT) section passes through the RPE tear and pigment epithelial detachment (PED). D) Fundus autoflorescence imaging 3 months after the RPE tear formation. 

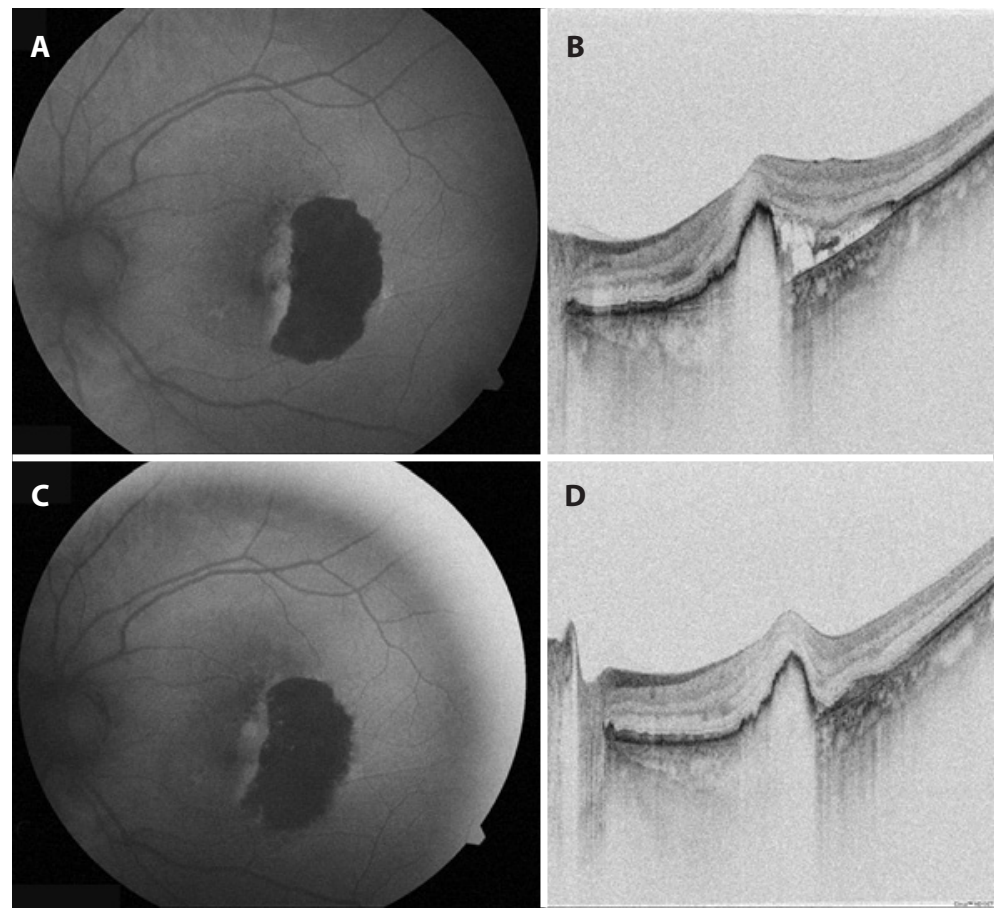

Figure 2. A) The initial fundus autofluorescent imaging of the RPE tear with two disc-sized hypoautofluorescent areas. B) The initial spectral domain optical coherence tomography (SD-OCT) with retinal pigment epithelium (RPE) tear. C) After three ranibizumab injections, hyperautofluorescent spots were observed in the hypoautofluorescent area, and D) the height of the pigment epithelial detachment (PED) was decreased.

bare Bruch's membrane for a few days ${ }^{(2,8,12)}$. After RPE tear formation, the PED usually becomes flat spontaneously. Reattachment of the free RPE edges to the Bruch membrane at a different location has recently been reported ${ }^{(2)}$. There is a possibility of improvement in patients with lower grade RPE tears ${ }^{(12)}$.

Overexpression of new tissue from the tear border provides solidity to the RPE layer. The intraretinal hyper-reflective spots in SD-OCT and the corresponding hyperfluorescent spots in fundus autoflorescence may be secondary to RPE migration ${ }^{(12)}$. The existence of the hyperautofluorescent spots may be similar to the ones in central serous retinopathy ${ }^{(16)}$. The reason for this is the corrupted pump mechanism in the RPE denuded region and phagocytosis in the outer segment. The hyperreflective spots in fundus autoflorescence imaging may represent the subretinal or intraretinal outer photoreceptor segments that are phagocytized by the macrophages because the photoreceptor cells can live up to 325 days in the RPE denuded area ${ }^{(17)}$. Moreover, it has been demonstrated that the precipitates in the subretinal outer segment layer acted as hyperreflective spots in OCT ophthalmoscopy of central serous retinopathy ${ }^{(18,19)}$.

Previous studies have reported repopulation and reattachment of RPE cells after tear formation, but these studies did not demonstrate healing of the hypoautofluorescence in the tear region ${ }^{(2,8)}$. Pece et al. used OCT to show that reattachment of the margins of an RPE tear were healed by tissue remodeling and described how the disease can recur ${ }^{(20)}$. In our study, reattachment of the RPE tear was demonstrated by using SD-OCT and fundus autofluorescence imaging only in 2 eyes. In addition, the hypoautofluorescent area in the tear region healed partially in one eye after 6 months. In another eye, hyperautofluorescent spots had appeared in the hypoautofluorescent area. Similarly, Caramoy et al. reported a case in which healing in the hypoautofluorescent area was observed after 2.5 years. In that study using SD-OCT, 7 (19.4\%) of 36 eyes showed patchy or hazy hyperfluorescent areas in fundus autofluorescence imaging, and the majority of the eyes (83.3\%) showed hyperreflective dots that possibly repre- sented hard exudates and intraretinal RPE migration. The authors stated that fundus autofluorescence imaging showed a considerable amount of RPE proliferation, repopulation, and migration ${ }^{(12)}$.

In a recent study that included 1298 AMD patients, the pooled rate of RPE tears was $1.8 \%$ in the 0.5 -mg ranibizumab group, $3.0 \%$ in the 0.3 -mg ranibizumab group, and $1.6 \%$ in the control group. Better visual acuity results were achieved with ranibizumab treatment versus control treatment in patients with RPE tears. Moreover, the potential benefit of continued ranibizumab therapy was suggested for patients with RPE tears secondary to neovascular AMD(21). Garg et al. reported that 15 eyes from 15 patients developed an RPE tear, which gave an incidence of $1.6 \%$ in 920 eyes with exudative AMD treated with intravitreal bevacizumab. Six of the 15 eyes were continued to be injected with bevacizumab/ranibizumab after tear development, and four of these six eyes showed visual improvement ${ }^{(22)}$. The risk for RPE tear after bevacizumab injection in eyes with PED seems to be moderate. Weinberger et al. investigated RPE tears after intravitreal bevacizumab in 31 eyes with PED and observed RPE tears in four eyes without vision loss. The authors concluded that continuation of anti-VEGF injections for patients who develop RPE tears during injection therapy seems to be necessary ${ }^{(23)}$.

In a few studies, certain factors, such as large PED diameter, vertical height, and subretinal fluid, have been associated with an increase in RPE tear rate ${ }^{(5,24)}$. The contour of the PED is an important factor for predicting RPE tear formation risk. Moroz et al. retrospectively evaluated 24 consecutive patients with choroidal neovascular membrane associated with PED, and reported the development of RPE tears after the first injection in six patients. They described two typical patterns in the eyes, which developed tears. One pattern was multifocal wrinkles and waves with RPE elevations, and the second was step-like interruptions of the continuity of the RPE line ${ }^{(25)}$. Knowing these risk factors is important for identifying eyes that are likely to develop this complication. The anatomical SD-OCT characteristics of a PED leading to RPE tear after anti-VEGF therapy has recently been descri- 
bed by Nagiel et al. and has been prospectively described by Sarraf et al. ${ }^{(26,27)}$. Eyes with vascularized PEDs secondary to AMD have a risk for RPE tear following intravitreal anti-VEGF injection. Those authors explained that the contraction of neovascular tissue adhering to the undersurface of the RPE and rapid involution may cause a substantial contractile force that tears this already-strained tissue layer ${ }^{(26)}$. A baseline PED height $>550 \mu \mathrm{m}$, presence of a Grade 1 tear, and positive ring sign are high-risk factors for the subsequent development of an RPE tear ${ }^{(27)}$. In our study, the mean PED height of eyes with RPE tears was $447 \mu \mathrm{m}$. In addition, before the development of tear formation, irregularity in the PED area was detected in seven of eight eyes with PED.

One of the patients in our study had choroidal neovascularization secondary to choroidal osteoma. Choroidal osteomas may decalcify and cause degeneration in the underlying retina, including the RPE. In this patient, the RPE tear occurred between the decalcified and calcified regions, which can be explained by the fragility of the area caused by degeneration of the RPE ${ }^{(28)}$. The RPE tear mechanism may be different for choroidal neovascularization secondary to choroidal osteoma. Sen et al. demonstrated that multiple anti-VEGF injections caused Bruch membrane rupture in angioid streaks in which the Bruch membrane was calcified and brittle, as in choroidal osteoma ${ }^{(29)}$. To our knowledge, our case is the first choroidal osteoma case to show the development of an RPE tear after ranibizumab therapy.

The limitations of this study included the limited sample size, lack of a comparison with a control group, lack of standard etiological and anatomical classifications, short follow-up period, and retrospective design. On the other hand, this was a single-center study and the same technicians performed the fundus autoflorescence imaging and SD-OCT, which may have helped to standardize the input. For distinguishing risk factors and mechanisms for RPE tear formation either spontaneously or after VEGF therapy, randomized studies in larger patient series are needed.

\section{CONCLUSION}

In our series, RPE tears developed mostly after intravitreal anti-VEGF injections administered to treat vascularized PED. The study results demonstrate that SD-OCT, along with fundus autoflorescence imaging, provided valuable information about the healing process of RPE tears. The continuation of anti-VEGF therapy after tear formation is beneficial for vision improvement in eyes with RPE tears. The PED height and irregularity in the edges of PED areas can be an early indicator of RPE tear formation.

\section{REFERENCES}

1. Ronan SM, Yoganathan P, Chien F, Corcóstegui IA, Blumenkranz MS, Deramo VA, et al. Retinal pigment epithelial tears after intravitreal injection of bevacizumab (Avastin) for neovascular age-related macular degeneration. Retina. 2007;27(5):535-40.

2. Moreira CA Jr, Arana LA, Zago RJ. Long-term results of repeated anti-vascular endothelial growth factor therapy in eyes with retinal pigment epithelial tears. Retina. 2013; 33(2):277-81.

3. Barkmeier AJ, Carvounis PE. Retinal pigment epithelial tears and the management of exudative age-related macular degeneration. Semin Ophthalmol. 2011;26(3):94-103.

4. Pece A, Introini U, Bottoni F, Brancato R. Acute retinal pigment epithelial tear after photodynamic therapy. Retina. 2001;21(6):661-5.

5. Chan CK, Meyer CH, Gross JG, Abraham P, Nuthi AS, Kokame GT, et al. Retinal pigment epithelial tears after intravitreal bevacizumab injection for neovascular age-related macular degeneration. Retina. 2007:27(5):541-51.

6. Bakri SJ, Kitzmann AS. Retinal pigment epithelial tear after intravitreal ranibizumab. Am J Ophthalmol. 2007;143(3):505-7.

7. Erol MK, Ozdemir O, Coban DT, Ceran BB, Bulut M. Ranibizumab treatment for choroidal neovascularization secondary to causes other than age-related macular degeneration with good baseline visual acuity. Semin Ophthalmol. 2014:29(2):108-13.

8. Chang LK, Sarraf D. Tears of the retina pigment epithelium: an old problem in a new era. Retina. 2007;27(5):523-34.

9. Smith BT, Kraus CL, Apte RS. Retinal pigment epithelial tears in ranibizumab-treated eyes. Retina. 2009;29(3):335-9.

10. Pece A, Vitale L, Milani P, Pierro L. Spontaneous reattachment of the margins of a macular retinal pigment epithelium tear: optical coherence tomography documentation of a case. Ophthalmologica. 2010;224(3):159-61.

11. Peiretti E, Iranmanesh R, Lee JJ, Klancnik JM Jr, Sorenson JA, Yannuzzi LA. Repopulation of the retinal pigment epithelium after pigment epithelial rip. Retina. 2006;26(9): 1097-9.

12. Caramoy A, Fauser S, Kirchov B. Fundus autofluorescence and spectral domain optical coherence tomography findings suggesting tissue remodeling in retinal pigment epithelium tear. Br J Ophthalmol. 2012;96(9):1211-6.

13. Sarraf D, Reddy S, Chiang A, Yu F, Jain A. A new grading system for retinal pigment epithelial tears. Retina. 2010;30(7):1039-45.

14. Gass JD. Pathogenesis of tears of the retinal pigment epithelium. Br J Ophthalmol. 1984; 68(8):513-9.

15. Singh RP, Sears JE. Retinal pigment epithelial tear after pegaptanib injection for exudative age-related macular degeneration. Am J Ophthalmol. 2006;142(1):160-2.

16. Erol MK, Özdemir Ö, Çoban DT, Karaçor A, Bulut M, Söğütlü Sarı E. Fundus autofluorescence in acute and chronic central serous chorioretinopathy. Turk J Ophthalmol. 2013; 43:94-8.

17. Caramoy A, Kirchhof B, Fauser S. Retinal pigment epithelium tears secondary to age-related macular degeneration: a simultaneous confocal scanning laser ophthalmoscopy and spectral-domain optical coherence tomography study. Arch Ophthalmol. 2011;129(5): 575-9.

18. Kon Y, lida T, Maruko I, Saito M. The optical coherence tomography-ophthalmoscope for examination of central serous chorioretinopathy with precipitates. Retina. 2008; 28(6):864-9.

19. Ozdemir O, Erol MK. Morphologic changes and visual outcomes in resolved central serous chorioretinopathy treated with ranibizumab. Cutan Ocul Toxicol. 2014:33(2):122-6.

20. Pece A, Vitale L, Milani P, Pierro L. Spontaneous reattachment of margins of a macular pigment epithelium tear: optical coherence tomography documentation of a case. Ophthalmologica. 2010:224(3):159-61.

21. Cunningham ET Jr, Feiner L, Chung C, Tuomi L, Ehrlich JS. Incidence of retinal pigment epithelial tears after intravitreal ranibizumab injection for neovascular age-related macular degeneration. Ophthalmology. 2011:118(12):2447-52.

22. Garg S, Brod R, Kim D, Lane RG, Maguire J, Fischer D. Retinal pigment epithelial tears after intravitreal bevacizumab injection for exudative age-related macular degeneration. Clin Experiment Ophthalmol. 2008;36(3):252-6.

23. Weinberger AWA, Thiel M, Mohammadi B, Theofylaktopoulos I, Thumann G, Walter P. Retinal pigment epithelium tears after intravitreal bevacizumab in pigment epithelium detachment. Am J Ophthalmol. 2007;144(2):294-6.

24. Chiang A, Chang LK, Yu F, Sarraf D. Predictors of anti-VEGF associated retinal pigment epithelial tears using FA and OCT analysis. Retina. 2008;28(9):1265-9.

25. Moroz I, Moisseiev J, Alhalel A. Optical coherence tomography predictors of retinal pig ment epithelial tear following intravitreal bevacizumab injection. Ophthalmic Surg Lasers Imaging. 2009;40(6):570-5.

26. Nagiel A, Freund KB, Spaide RF, Munch IC, Larsen M, Sarraf D. Mechanism of retinal pigment epithelium tear formation following intravitreal anti-vascular endothelial growth factor therapy revealed by spectral-domain optical coherence tomography. Am J Ophthalmol. 2013;156(5):981-8.

27. Sarraf D, Chan C, Rahimy E, Abraham P. Prospective evaluation of the incidence and risk factors for the development of RPE tears after high- and low-dose ranibizumab therapy. Retina. 2013;33(8):1551-7.

28. Gass JD, Guerry RK, Jack RL, Harris G. Choroidal osteoma. Arch Ophthalmol. 1978;96(3): 428-35.

29. Sen PR, Rishi P, Sen P, Rishi E, Shroff D. Rapid progression of angioid streaks following intravitreal bevacizumab. Can J Ophthalmol. 2009:44(5):e39-40. 